\title{
Challenges Blockchain Technology and Initial Coin Offering (ICO) in Healthcare from Legal Perspectives
}

\author{
Wan Mohd Hirwani Wan Hussain
}

\begin{abstract}
This paper reviews the empirical literature on Initial Coin Offering (ICO), blockchain technology and impact for healthcare based on legal perspectives. The rise of blockchain technology has given impact especially on financial sector and business, there are very limited research been done about the implications of this technology in healthcare sector. Based from the literature it shows that it is still scarce about blockchain and initial coin offerings in healthcare industry. The scope of this article is twofold which is i) to understand the impact of blockchain technology and initial coin offering in healthcare industry; and 2) to understand the legal challenges especially in initial coin offerings. The revolution of blockchain technology will provide more positive impact in healthcare sector and can be used as new strategic directions for future research.
\end{abstract}

Keywords: Initial Coin Offering (ICO), Blockchain technology, Healthcare management system, legal, digital tokens, digital coins.

\section{INTRODUCTION}

Blockchain technology is one of the more recent technologies used for creating immutable and distributable data records which are shared on peer-to-peer networks. In blockchain technology, there are public data, private data and consortium data networks. Generally, the technology records digital events which allow relevant data to be exchanged and recognised until they reach the recipient. In many ways, blockchain technology is designed to increase data protection and secure relevant information from breach. A growing number of researchers have discussed the use of the blockchain technology in the financial sector as opposed to other fields. Banks are increasingly adopting this technology to protect their consumers and save operation costs. The blockchain network ensures improved operation and data entry without compromising other sensitive data. It should be noted here that the network is decentralised and have to be maintained by the users themselves - they do not have to rely on other organisations for storage. A research conducted by Silicon Republic demonstrates that, blockchain company start-ups raised US $\$ 1.4$ billion in 2016 and US $\$ 4$ billion in 2017. In the financial world, the revolution of blockchain technology in 2008 led to the creation of the Bitcoin

Revised Manuscript Received on December 30, 2019.

* Correspondence Author

Wan Mohd Hirwani Wan Hussain*, Graduate School Of Business, Universiti Kebangsaan Malaysia, 436000, Bangi, wmhwh@ukm.edu.my

(c) The Authors. Published by Blue Eyes Intelligence Engineering and Sciences Publication (BEIESP). This is an open access article under the CC BY-NC-ND license (http://creativecommons.org/licenses/by-nc-nd/4.0/) cryptocurrency ${ }^{1-8}$. It should be noted here that the first commercial transaction employing Bitcoin was used to buy two pizzas ${ }^{9}$. Following the financial crisis in 2008 , the rise of this new technology impacted the financial and business sectors greatly. The blockchain technology which revolutionised Bitcoin have transformed traditional financial services all over the world ${ }^{10-13}$ The financial sectors have attempted to adopt the blockchain technology by replicating this new technology to raise capital. One of the mechanisms that have been introduced is Initial Coin Offerings (ICOs) 13-16. ICO was mainly introduced to raise capital for companies, especially start-ups. From the perspective of companies, this technology has facilitated the ease of raising capital from the public. During 2017 for instance, ICO raised around US\$4 billion in the United States and the number increased more in 2018. According to Economist.com, ICO funding has become a big business and generated more than US $\$ 17$ billion in the first quarter of 2018. Researchers ${ }^{17}$ observe that ICO will surpasses many venture capitals and other technology companies aiming to raise capital in the financial markets. A number of studies have been conducted to analyse the impact of blockchain technology, especially from the perspective of economy and healthcare fields $2,9,10,18-21$, and also to explore its impact on traditional market failures and metadata transactions ${ }^{19,21-23}$. Cryptocurrencies have attracted attention from policy makers and institutions that want to study more about related topics ${ }^{24-29}$. Most of the literature studies note that blockchain is a reliable network which is generally secure from hackers. However, there is evidence that hackers have been able to exploit this new technology. For example, in 2014, Japanese Platform Mt Gox was attacked and some US\$50 million was stolen ${ }^{30,31}$. The first ICO, otherwise known as master coin, was originally introduced by J.R Willet in 2013, raising up to US $\$ 500,000$ of bitcoin ${ }^{8}$. According to CoinSchedule.com, during 2018, more than 1076 ICO have been introduced and collectively raised up money more than US $\$ 21$ billion from the public. Unlike the United Kingdom and the European Union (EU), relevant ICO regulations have been discussed in Singapore, Hong Kong, Australia, Canada and United States. These countries seek to understand the principle and impact of ICO to ascertain legal jurisdiction, and only China imposed an outright ban on ICO in $2017^{32}$. The ban imposed in China has significant impacts on the financial and economic market, but it is an efficient strategy to protect investors and control market speculations. The legal regime in the United Kingdom and European Union is slow compared to other countries, because ICO principles are somewhat complex and require a lot of procedures to achieve thorough understanding of its functioning. 
During 2017, China made a drastic move by banning all ICO, because of their destructive impacts on financial markets all over the world. This decision has influenced ICO price and market sentiment, because the ICO market is based on speculative emotion. The use of blockchain technology just like virtual currencies such as bitcoin has erased the function of central authorities e.g., banks and other financial institutions. Bitcoin enables users to hold and send money online by utilising the distributed ledger technology without the third party; this could make financial institutions become vulnerable. It is estimated that blockchain technology could reduce and save bank operation to the tune of US $\$ 20$ billion annually by $2022^{20,33,34}$. However, it should be noted here that it would take some time for the changes to take effect ${ }^{35}$.

This paper seeks to assess the implications of Initial Coin Offerings for the Healthcare sector, and how ICO could be used as a mechanism and tool to raise capital. This paper also will look into the structure and types of ICOs related to healthcare sectors. Also, effort will be made to examine the challenges ICOs face within the scope of legal regulation, such as money laundering, data protection and intellectual property law. Next, this paper will provide some ideas on aspects of ICO which could shape the healthcare sector, and concludes by suggesting relevant ideas and policy recommendations for future research.

\section{BLOCKCHAIN TECHNOLOGY}

Blockchain is the new rising technology that utilises distributed ledger and is managed by peer-to-peer networks $5,25,36$ and this technology is considered as a giant share datastore and store data in secure and protected network (https://bitcoin.org/bitcoin.pdf). Generally, blockchain technology seeks to make transactions more organised and protected from third party intervention. Relevant blockchain transactions are organised into a block and are linked together into a chain network. Using blockchain technology, transactions are validated and recorded using peer-to-peer networks; in this way, the relevant networks will prevent potential hacking and manipulations by third parties. This mechanism will make the network more secure, and further increase confidence and trust; also, all transactions will be recorded and verified in real time. Once a transaction has been verified, the record will be saved in the network and permanently stored in the blockchain network. This is the uniqueness of the blockchain technology compared to traditional financial systems.

The characteristics of blockchain technology is unique compared to traditional financial systems. It comprises of:

a) Security and data privacy: data stored will be stored in public and private key addresses. The public key will be revealed and the private will only be known by the users. If a third party manages to get the private keys, they can get access to the content ${ }^{6,37,38}$.

b) No Third Party: Compared to the traditional financial system that requires bank as intermediaries to transfer and acknowledge transactions, blockchain technology requires no third party monitoring; this is the major impact for financial institutions and would affect the money evolution in the future ${ }^{39-41}$.

c) Anonymous: The transaction in the blockchain network is anonymous and cannot be traced. In 2017, Ransomware attack damaged financial and healthcare institutions by "kidnapping" data from the users network ${ }^{42,43}$. The data will be encrypted and in order to access it the users must pay a certain amount of bitcoin 43,44 . Since it is anonymous, the young millennials prefer to use it compared to traditional financial systems ${ }^{5,45}$.

d) Proof-of-Work (PoW) and Proof-of-Stake (PoS): Proof-of-Work is the concept of consensus in blockchain network. By using this PoW relevant miners can confirm the transaction and produce new block in chain. With regard to Bitcoin, when users send the currency to other users, that transaction will gather into a block and the miners will confirm the transaction by solving a complicated mathematical puzzle; this process is known as mining. Miners who manage to complete the transaction in the network will get rewarded. Proof-of-Stake (PoS) is different from Proof-of-Work because there is no reward when miners solve it. Compared to PoW, the principle of PoS has been used in Ethereum blockchain because it saves energy and is less vulnerable to network attack $46-48$

e) Transaction will be stored and validatedBlockchain can be considered as a "privacy-by-design" peer-to-peer infrastructure ${ }^{29}$. Most of the cryptocurrencies can be stored on a wallet, either in software or physical forms where information relating to transactions, amount and addresses can be stored. New transactions must be validated by all the network users before it may be added to the blockchain network ${ }^{49,50}$.

The growing rise of Bitcoin cryptocurrency had led to the disruption in financial industries ${ }^{51}$. The blockchain technology is not only employed to raise capital but also can be used to develop new ecosystem for new businesses. The Fig 1. below shows the summary of ICO based on the fundraising, investing, community building and open sourcing category $41,52-54$. This research shows that blockchain technology has been used by entrepreneurs as the mechanism for raising capital by introducing tokens and without token concept.

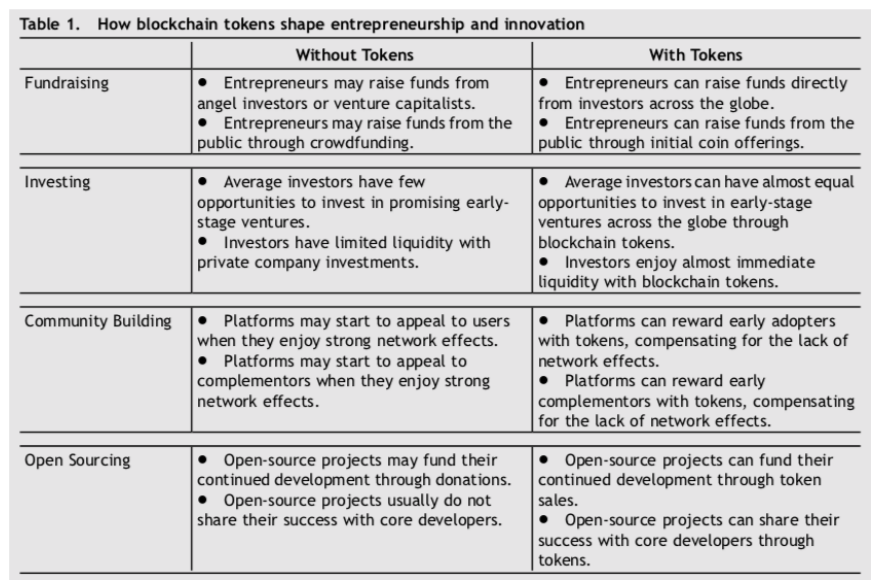

Fig 1: Taken from: ${ }^{55}$ 
Generally, certain blockchain tokens or digital tokens are given away or must be pre-ordered before launch; and there are tokens that use profit-sharing crowdfunding campaigns $21,56,57$. By capitalising ICO, most of the developer blockchain tokens can offer directly their digital tokens to the public and bypass the traditional intermediaries such as venture capitals or investment bankers. This will enable the digital token to raise capital more easily and make it appealing to global investors around the world ${ }^{58}$. Blockchain technology was technically designed as a cryptocurrency as it is the new way of storing the metadata of relevant transactions. Bitcoin transactions can only support 80 bytes of metadata compared to other blockchains such as MultiChain or Bigchain. The digital token is created based on the blockchain technology, and it is being monitored by smart contracts ${ }^{59,60}$. One of the most promising technology in blockchain is smart contracts that use Ethereum cryptocurrency which allows users to strore and transfer Ethereum on their peer-to-peer network. This Ethereum can also be used to develop decentralised applications (Dapps) that can be utilised to pay for any application provided in the Ethereum platform. Microsoft company adopted the Ethereum technology on the platform Azure, and as of January 2019, it is the third largest market besides Bitcoin (US\$63 billion market cap) and Ripple (US\$13 billion market cap). Besides these three coins, there are other cryptocurrencies such as Bitcoin Cash (US\$2 billion market cap), Stellar (US\$2 billion market cap), Litecoin (US\$1 billion market cap) and many more, as shown in Fig. 2 below.

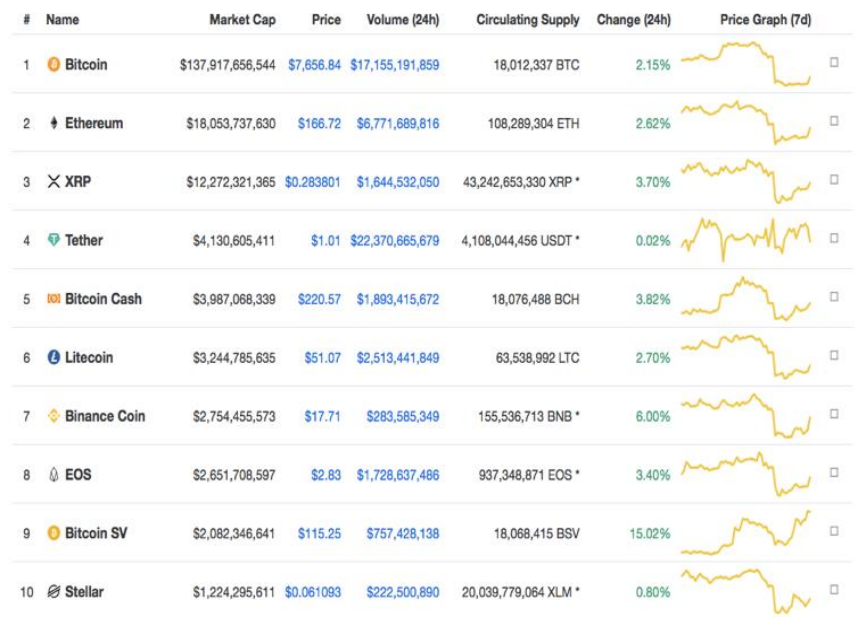

Fig 2: CoinMarketcap.com

\section{WHAT IS INITIAL COIN OFFERING}

ICO started to gain traction following the emergence of blockchain technology within the cryptocurrencies ecosystem. In the past 24 months, more than 3000 ICOs have been launched on the internet. The ICO for Telegram has raised more than US\$1.7 billion, and the funds for ICO is expected to surpass US\$75 billion. Many start-up companies have realised the potential of ICO to fund their project and raise needed capital by offering digital tokens/assets to the public. In 2013, Mastercoin (now better known as OMNI) raised more than US\$5 million in capital from the first ICO, and since then most project developers have used this mechanism to attract investors to invest in their project. For example, celebrities such as Paris Hilton launched LydianCoin andJamie Fox launched Cobinhood to raise up money for their ICO coins ${ }^{61}$. Investing in ICO is not only based on the project or blockchain technology that is introduced but is mostly based on speculation and marketing strategy just like when the Internet booming in 2000. Since 2017, some other industries such as restaurants, cloud computing, games and internet of things, have been using ICO as the mechanism to raise capital, unlike 2014 when ICO was mostly utilised by tech companies. Figure 3 shows the ICO category that was introduced in 2018 and the top three category included infrastructure, finance and communications.

Furthermore, the category of ICO also related to payment, gaming \& virtual reality (VR), governance, events and entertainment, commerce and advertising and many more.

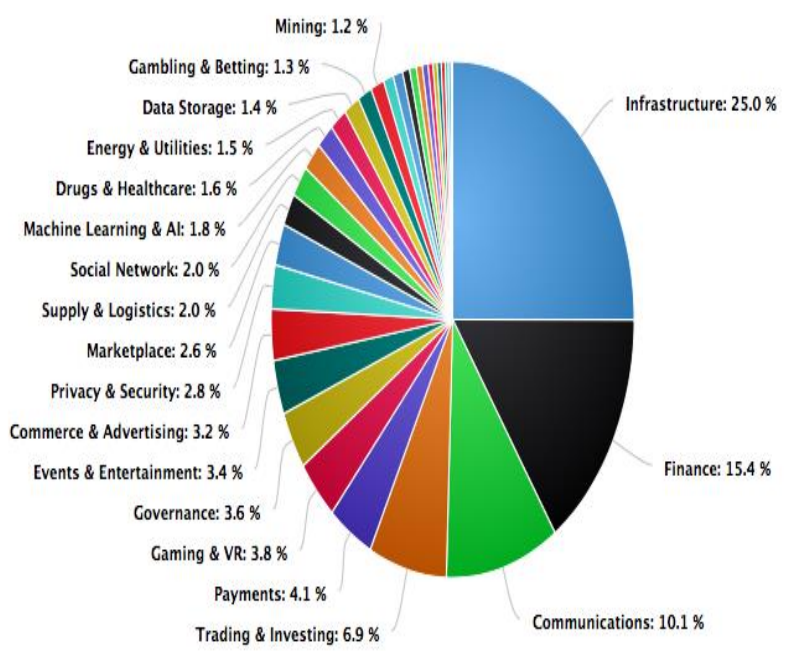

Fig 3: CoinSchedule.com (ICO by category in year 2018)

The process of launching ICO to the public must follow certain steps and procedures based on Fig. $4{ }^{32}$. It is worth noting, however, that where regulation and monitoring is weak, ICO may be susceptible to fraud such as Ponzi scheme, money laundering and others.

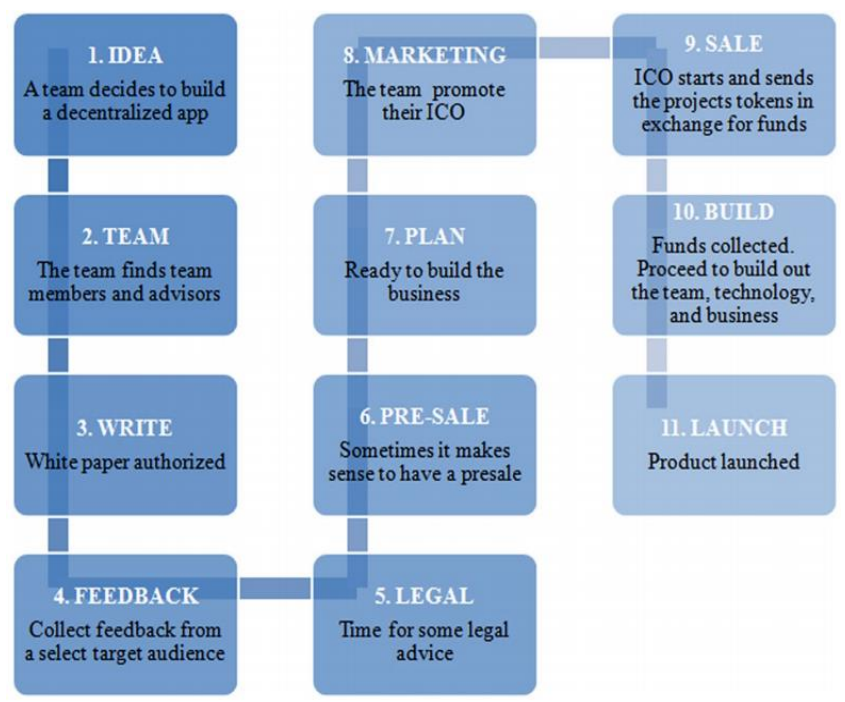

Fig 4: Taken from ${ }^{32}$ 


\begin{tabular}{cc}
\hline Country & ICO Origin \\
\hline USA & 1031 \\
\hline China & 452 \\
\hline Russia & 310 \\
\hline Singapore & 260 \\
\hline Israel & 192 \\
\hline Germany & 187 \\
\hline Canada & 175 \\
\hline UK & 145 \\
\hline Switzerland & 64 \\
\hline Estonia & 63 \\
\hline Table 1: taken from &
\end{tabular}
blockchain because it is flexible and user-friendly, and can help design new tokens and many useful applications. Also, Ethereum blockchain can be used to create decentralised applications and smart contract and is universally accessible for running business ${ }^{48,63}$. Table 1 shows the top 10 countries for ICO projects based on Ernst and Young Research Data from 2017. The table demonstrates that the USA has 1031 ICO projects China 452, Russia 310 ICO projects Singapore 260 ICO project and the lowest ICO projects is by Estonia for 63 projects. However, China started banning all ICOs in 2017 because investors were exposed to high risks, and the ICOs promoted scam and fraudulent investment. Generally, the year 2017 was a landmark year for ICOs because they became popular and the majority of funds were raised and collected using this technique ${ }^{64}$. In defining the concept of ICO, Research by ${ }^{65}$ distinguishes four types of tokens based on the source and underlying value:

a) Traditional asset tokens: These tokens represent traditional assets such as equity and real estate which are the most common types of tokens. Example of this token includes USDT (Tether).

b) Usage tokens: These types of token require access to the protocol and payment must be made for the service. Examples of usage token include BTC (Bitcoin) and ETH (Ethereum).

c) Work tokens: This is the type of token given to holders to contribute to the decentralised organisation and can help relevant organisations to function effectively. Examples of this token include REP (Augur) and MKR (Maker).

d) Hybrid token: This token is the combination of usage and work tokens. An example of this tokens is Ethereum blockchain; when it switches from proof-of-work (POW) to proof-of-stake (POS) protocol it becomes hybrid because it gives users the right to validate and earn ETH in exchange

\section{METHODOLOGY}

In this research, we are using technique literature review as the foundation to gain understanding about the blockchain technology article based from literature. We are utilizing database from Scopus.com, Web of Science and ScienceDirect.com as the database for literature review. The keywords blockchain technology, initial coin offering and ICO. The data that gain were extracted from all eligible studies based on the reported study information, the endpoint data and also the robustness from the data. The studies will be
Most of the ICOs were developed using the Ethereum for their work.

divided into different section based on the legislation and medical fields to understand the pattern of the data and this will be analysed in the next section.

\section{APPLICATION OF BLOCKCHAIN TECHNOLOGY IN HEALTHCARE MANAGEMENT}

It should be noted here that the blockchain technology has been mostly utilised in the financial sector. However, the technology can also be used in the healthcare sector in areas such as managing healthcare database, data storage, payment gateway, data privacy and security. There are also a case that shows relevant data have been stolen and "kidnapped" (Ransomware) in the healthcare sector and users have to pay certain amount via bitcoin to unencrypt the data $43,44,66$. It is safe to argue that the blockchain technology is here to stay. Instead of harming health systems, it can be useful for research and development in healthcare. This section will examine the application of blockchain technology in healthcare. There are many start-up companies working on blockchain technology. Table 1 (below) indicates some of the start-up companies utilising blockchain technology for data security, data management etc.

\begin{tabular}{|c|c|}
\hline $\begin{array}{ll}\text { Start-Up Company } \\
\text { Healthcare } \\
\text { Blockchain }\end{array}$ & Information \\
\hline 1. GuardTime & $\begin{array}{l}\text { GuardTime helps to secure patients' data } \\
\text { and healthcare records. Patients can access } \\
\text { their data using their smart phones. More } \\
\text { information can be obtained from } \\
\text { https://guardtime.com/ }\end{array}$ \\
\hline 2. Nebula Genomics & $\begin{array}{l}\text { This start-up company utilises the } \\
\text { biomedical big data by giving users rewards } \\
\text { and credits when they participate in the } \\
\text { genomics research for this blockchain } \\
\text { company. The company protects relevant } \\
\text { data and privacy of the user anonymously. } \\
\text { https://www.nebula.org }\end{array}$ \\
\hline 3. Iryo Network & $\begin{array}{l}\text { Open healthcare protocol is utilised here; } \\
\text { medical data are also provided and } \\
\text { exchanged securely between patients and } \\
\text { organisations. The data will remain private } \\
\text { and secure in the blockchain network. } \\
\text { https://iryo.network }\end{array}$ \\
\hline 4. MedRec & $\begin{array}{l}\text { This is a blockchain based system network } \\
\text { that secures medical records; it utilises smart } \\
\text { contracts, MedRec records and store } \\
\text { medical record so that patients can access } \\
\text { their records securely. } \\
\text { https://medrec.media.mit.edu/ }\end{array}$ \\
\hline 5. Block Pharma & $\begin{array}{l}\text { Block Pharma is a French start-up that } \\
\text { employs the blockchain technology to fight } \\
\text { drug counterfeiting. The use of blockchain } \\
\text { technology can trace back the } \\
\text { manufacturing of drug development along } \\
\text { the supply chain and is able to detect fake } \\
\text { drugs before they are released to the market. } \\
\text { According to their website } \\
\text { https://www.blockpharma.com/, around } \\
800,000 \text { people have died as a result and } \\
\text { consequence of counterfeit drugs }\end{array}$ \\
\hline
\end{tabular}

i) Clinical level: At the clinical level, the blockchain technology can be used to store and secure information in the metadata and prevent hacking or data manipulation. This information can be used by medical practitioners, medical students, and researchers to diagnose/analyze the right information and data in real time.

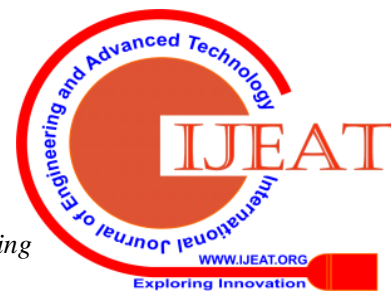


The stored data will be validated in the network and any revision must get permission from the network. Figure 6 shows that smart contract can represent the piece of code that can be programmed without intervention from third party. Using this mechanism could increase patients' trust in the system and could facilitate data analysis. Each of the data can be summarised to compile the result for the clinical step level 67. Generally, criminals cannot manipulate relevant data in blockchain network ${ }^{68}$.

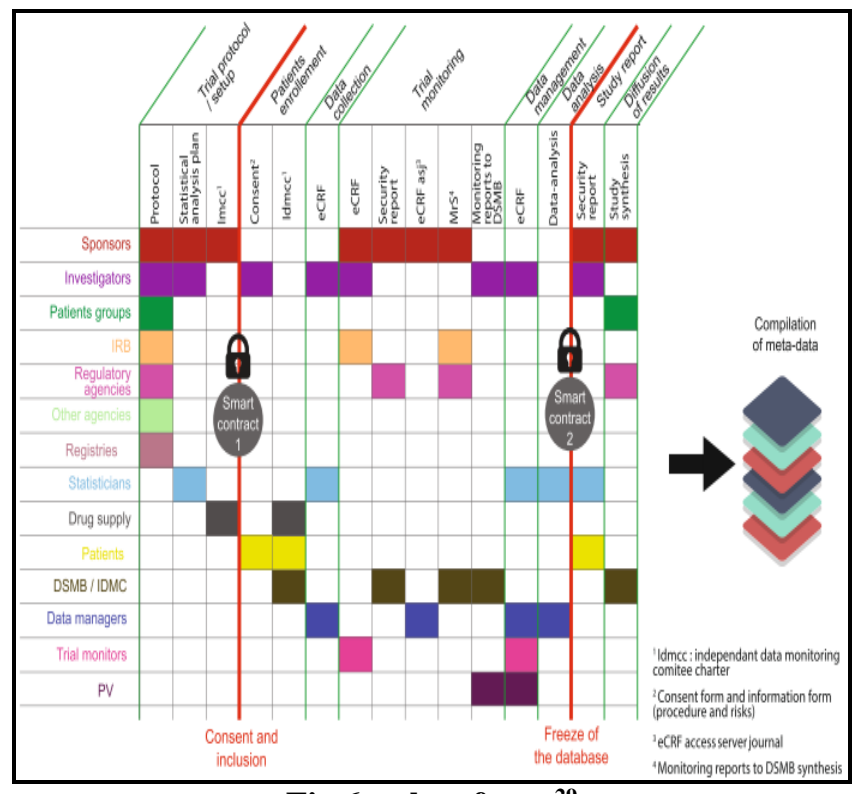

Fig 6: taken from ${ }^{29}$

i)Patient Level: From the patient's perspective, blockchain technology can help to secure data; such data may be accessed by doctors, patients and insurance companies. However, in order to distribute the data to the network, the consent of the patient must be obtained and the patient's rights must be protected. The development of smart contract in the healthcare sector is important because it can create binding agreement and maintain the relationship between doctors and patients ${ }^{69}$. Introducing smart contracts application can also prevent data manipulation and could facilitate transaction between the parties without third party intermediaries.

ii) Teaching Level: Teaching ICO at the university and school level could be highly beneficial. Students will expose themselves to the new knowledge on how ICO can be used to raise capital for the business. Teaching blockchain network at university and school can enhance student learning experience and demonstrate their capabilities to acquire new knowledge ${ }^{70-72}$. University researcher can develop online learning education based on the course such as smart contract, Internet of Health Things (IoHT), $4^{\text {th }}$ Industrial Revolution, Augemented Reality or Virtual Reality to learn about this new technology.

iii) Research and Publication: The study of blockchain technology and healthcare have increased since $2014{ }^{73}$, and most of the research focus on smart contracts ${ }^{74-76}$. Internet of Things (IoT) ${ }^{29,77,78}$, smart city ${ }^{79,80}$, Big Data Analytics ${ }^{26,81,82}$ and health care system ${ }^{83-85}$ are the emerging issues that can be researched apart from ICO technology. Publications related to ICO in the healthcare ecosystem can help understand the nature and impact of ICO in healthcare, especially those relating to law and policy. The use of blockchain technology can also help in peer review article system because it is more efficient and reliable. A monetary compensation mechanism be designed using blockchain network as a reward for reviewers, researchers and editors, as publications fees can be used as a cryptocurrency ${ }^{86}$. In fact, journals such as Ledger (http://ledgerjournal.org) have been established to cover the issues related to blockchain technology.

iv) Medical Insurance Claims: The blockchain network helps in securing and managing data more easily, thereby allowing both medical practitioners and insurance companies verify the data to ensure efficient services. The data will be recorded and encrypted such that it becomes impossible to change and be removed from the network. This method allows for data integrity and can help in verifying Patient Health Information System (PHI), prove the medical clinical result ${ }^{87}$ and improve the medical audits ${ }^{88}$. Also, it can help in reducing the audit expenses as it is a form of regulatory compliance $^{88}$.

v) Smart Contracts: The uniqueness of blockchain technology is the smart contracts application. Smart contract is the code that runs in the blockchain network that facilitates, secure and also enforce the terms in the agreement. The main aim of smart contracts is to automatically enforce the agreement when the conditions are met. Compared to traditional contract, smart contracts are automatic, do not need third parties, transition fees are low and are secure in the blockchain network. The concept of smart contract was introduced in 1994 by Szabo, and Ethereum is the most popular platform being used for smart contract application, distributed applications and decentralised applications (dApps) from social network, gaming application, virtual technology application and many types of financial applications $47,89,90$.

\section{RESULT ANALYSIS}

\section{Investor Issue}

The decentralised, open and cryptographic nature of blockchain will help customers to make any online transactions without being tracked by relevant authorities. In the case of United States $v$ Ross William, also known as the Silk Road Case, Bitcoin was utilised for drug trafficking purposes, and even though the blockchain could record the transaction, it was impossible for the Federal Bureau of Investigation (FBI) to trace the identities of sellers and buyers. This concepts also can be used when launching new ICO in the market and the money generated from ICO are potentially being used in illegal activities such as fraud, money laundering schemes, online Ponzi scheme, tax evasion and so forth. For investors, ICO can also be used for phishing techniques to fraudulently impersonate ICO. Using this technique, the funds that accrue from the ICO can be transferred to other non-traceable accounts and this will put investors at risk. Hackers can also hack into personal investor computers and can steal valuable information, and there is lack of systems or regulations that can protect investors from losing their investment. The investor is on the losing side and vulnerable, because no organisation or authority audits and monitor the ICO before it is launched to the marketplace.

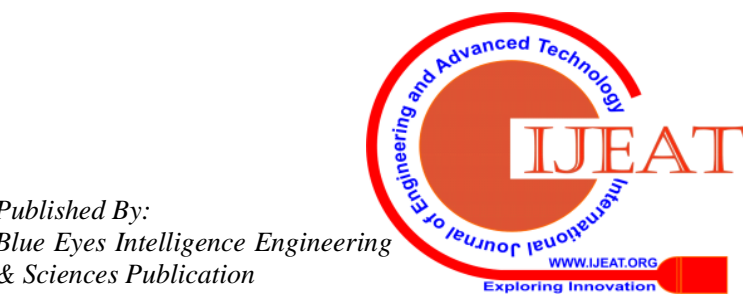




\section{Market Issue}

Since there is no protection for the investor, there are also risks for the markets dealing in ICO. Risks relate to price manipulation, speculative market without control of central authority and the governance structure of ICO. Different countries have different jurisdictions and legal authority. However, with regard to cryptocurrencies, the market is volatile, is based on speculation and can be easily manipulated. Most of the technologies in ICO are based on the free market and are anonymous; thus, it is difficult for the government to control new ICOs in the market. Furthermore, the total market supply for ICO can be manipulated by developers; for example, developers can create a new volume of market capital for the ICO because there is no central authority that monitors and govern it ${ }^{13,91}$.

\section{Money Laundering Issue}

Despite its huge benefits, application of ICO in blockchain is also faced with some challenges such as money laundering activities. For example, the financial action task force reported that in 2015, the founder of liberty reserves used the money to fund a criminal organisation. Criminals, in turn, use ICO to fund illegal activities such as online gambling, online Ponzi scheme, get rich quick scheme, and also drug dealing activity online. Silk Road is also well-known in the underworld black markets such as "darknet". Darknet is a website that deals in illegal activity online ${ }^{92}$. This website accepts cryptocurrency as a payment to do illegal activities from drug to hitmen ${ }^{93,94}$.

In the digital ecosystem, laws must be applied in the context of legal codes and software to govern all digital activities. Relevant laws and regulations must be able to measure how far and fast technology should develop. The legal requirement needs to balance and minimise potential risks especially to the health care system.

\section{Regulation Issue}

The United States was the first country to regulate, monitor, and legalise cryptocurrency and ICO. In this regard, it is worth noting that the United States is more advanced than other countries including the United Kingdom and the European Union. For the most part, the US government treated cryptocurrency as a "medium of exchange that can use as currency, commodity and security". For example in the case of State of Florida v. Michell A. Espinoza ('Espinoza'), the court decided that Bitcoin cannot be treated as money but as a "virtual currency", because it has high volatility and limited ability. This decision has been supported by the Inland Revenue Service (IRS) that states that "virtual currency" can also be used for tax purposes. It should be noted that tokens must be differentiated from currency, utility and investment tokens. In theory, the various types of tokens that been introduced as ICO must fall under investment tokens. Tokens that are issued as ICO may have an investment component that promise future positive return from the investor; these must be considered and legalised under securities law.

The Securities and Exchange Commission (SEC) of the United States is the agency that controls and regulate all the operations related to the securities market. One of the main task of SEC is to monitor the cryptocurrency market and any investment that relates to ICO. In the case of Decentralised Autonomous Organisation (DAO) tokens, SEC concluded that DAO token was a security and any sale related to the token were subject to the US federal securities law. DAO tokens were based on the smart contract and designed to function as a community-managed venture fund without owner or managers and the launching of its ICO generated about 12 million Ethers ${ }^{95}$. In the DAO case, the SEC referred to the case SEC $v$ W.J Howey Co, where it was mentioned that a specific test known as "Howey Test" must be fulfilled 96 which is: (1) an investment of money (2) in a common enterprise (3) with the expectation of profit and (4) to come significantly from the efforts of others. The SEC came to the conclusion that DAO tokens are considered as securities, and DAO tokens also not been registered at broker-dealer funding portal to be considered as crowdfunding contract.

In Canada, the establishment of Canadian Securities Administrators (CSA) can help in monitoring ICO based on the Securities Law ${ }^{96}$. CSA regulations indicate that "digital tokens" or any similar future business that represent shares in a company or similar ownership can be governed under Securities Law. The legal jurisdiction in Canada also seeks to protect the interest of investors when they invest their money, and ICO will be subjected to the Securities Law. In the case Pacific Coast Coin Exchange v. Ontario Securities Commission ('Pacific Coast'), the court decided that 'commodity account agreements' is under securities law. In this case, Pacific Coast sold silver coins on TV and traded in 'commodity account

agreements' for the purchase of silver coins on margin. In this case the investors entered "commodity account agreement" however most of them never received payment and never took any possession of silver coin. The nature business of Pacific Coast business was based on speculation market of of silver prices and the court decided it constituted security. The court also referred to the "Howey Test" based on the case SEC $v$ W.J Howey Co.

In Europe, the European Parliament voted to adopt smart-regulatory hand-offs approach that can regulate blockchain technology ${ }^{97}$. On its part, the EU Parliament wants to monitor cryptocurrency and money laundering activities. The EU seeks to achieve technical expertise and understand the technology before proposing any specific regulations ${ }^{98}$. In Australia, the Australia Securities \& Investment Commission proposed specific guidelines indicating that ICO could be managed as investment scheme, a share in a company, and a derivative or non-cash payment; but it must refer to relevant laws. Laws in Australia are much wider and broader compared to the United States, because they are an amalgam of other laws such as company law, contract law and security law. Similar to the United States, Canada and Australia, Singapore has also focussed on developing and regulating ICO. The country's financial regulatory body known as the Monetary Authority of Singapore (MAS) introduced "A Guide to Digital Token Offerings" on 14 November 2017 and declared that ICO will fall under Singapore's Securities and Futures Act (SFA). Singapore has emerged as the leading hub for ICOs in Asia and has the third-largest ICO in the world ${ }^{32}$. Several ICOs have been launched in Singapore such as Digix and Tenx. Generally, Singapore is taking the regulation and monitoring of ICO very seriously compared to most countries in Asia.

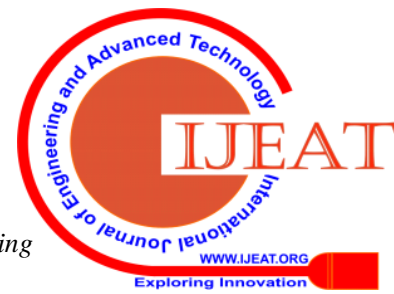


Law and regulations must be balanced and adapt fast with emerging technologies and new environment. Law and technology must contribute to the system and protect investors especially regarding ICO associated risks, investor right, fraud scheme and so forth. Future regulatory frameworks must adopt a multi-governance approach that can include many participants, thereby providing better solutions from civil officers, education institutions, financial institutions and the wider society.

\section{FUTURE RESEARCH}

The healthcare field is the most promising sector in blockchain technology. New data must be analysed in real time and managed in electronic health care systems. It is currently unclear whether ICO or digital tokens can become the payment gateway for patients or hospitals around the world. Patients' personal data must be protected from hacking or "kidnapping". Indeed, what does protection mean for patients if their data is being breached or compromised? Also, the understanding and technological capabilities from third world countries remain unclear and need to be researched in the future.

In many ways, such applications in emerging areas like financial transfers, multi-signature transactions, 'coloured coins', property registers, intellectual property, smart contracts, other data stored in the blockchain, decentralised organisations, and securities and financial products could complicate the legal landscape ${ }^{17,99,100}$. Cryptocurrencies have advanced the boundaries of current laws and compelled a change in approach to regulation.

\section{CONCLUSION}

It is without a doubt that ICO must be regulated and monitored by central legal authorities. The technology revolution will be very fast and legal authorities must be well-equipped and up-to-date with current issues. This paper has attempted to provide an overview of blockchain technology and ICO in healthcare. ICO has effectively changed the landscape in finance and business environments. It has also helped in raising capital for new start-up companies. While this new ecosystem could affect the entire healthcare system, disrupt the financial industry and affect governments, it could also create new paradigms that shape the Digital Economy. Certain countries, in particular, China have placed a ban on ICO, and other countries like the United States, Singapore, Australia and Canada are more ICO friendly because they understand its impact for the financial and healthcare ecosystem. The impact of ICO will mostly relate to legal application, for example privacy law, anti-money-laundering law and security law. This paper seeks to help regulators and policymakers better engage with ICO in the area of healthcare without harming the customer, patient, investor while at the same time providing stability in the healthcare system.

Finally, it is worth pointing out that this paper is not without some limitations; relevant limitations include data accessibility and generalisation of results. It should be noted here that most of the data were collected from many sources and websites such as CoinMarketcap.com, CoinSchedule.com and many more. The data from these websites provide evidence regarding ICO, and the writer always cross check the evidence with other relevant sources. The concept of ICO and the regulation is still unclear and are currently at the early stages. The result here may be different when relevant countries have accepted and adopted the digital tokens in their transactions. When this happens, it will impact the entire healthcare ecosystem. However, at present, ICO is still considered as the new mechanism to raise capital compared to IPO (Initial Public Offering) or any other crowdfunding techniques and strategies. As countries such as the United Kingdom and the EU remain silent, there is still a long way to go in regulating and understanding the fundamental impacts of ICO.

\section{ACKNOWLEDGEMENT}

This research was supported by the Universiti Kebangsaan Malaysia (UKM) and Graduate School of Business (UKM-GSB) under four research grant UKM Research Grant GSB-2018-015, UKM Research Grant GSB-2018-003, UKM Research Grant GIP-2018-002, UKM Research Grant DCP-2017-005/2.

\section{REFERENCES}

1. Treleaven, P., Brown, R. G. \& Yang, D. Blockchain Technology in Finance. Computer (Long. Beach. Calif). (2017). doi:10.1109/MC.2017.3571047

2. Bargar, D. The Economics of the Blockchain: A study of its engineering and transaction services marketplace. All Theses (2016).

3. Iansiti, M. \& Lakhani, K. R. The truth about blockchain. Harvard Business Review (2017). doi:10.1016/j.annals.2005.11.001

4. Catalini, C. \& Gans, J. S. Some Simple Economics of the Blockchain. SSRN (2016). doi:10.2139/ssrn.2874598

5. Stratiev, O. Cryptocurrency and Blockchain: How to Regulate Something We Do Not Understand. Bank. Financ. Law Rev. (2018).

6. Giungato, P., Rana, R., Tarabella, A. \& Tricase, C. Current trends in sustainability of bitcoins and related blockchain technology. Sustainability (Switzerland) (2017). doi:10.3390/su9122214

7. Halaburda, H. Blockchain Revolution Without the Blockchain. SSRN (2018). doi:10.2139/ssrn.3133313

8. CB Insights. Blockchain Investment Trends in Review. CB Insights (2018).

9. Gibson, C. T. \& Kirk, T. Blockchain 101 for Asset Managers. Invest Lawyer (2016). doi:10.5539/ibr.v8n8p59

10. Arner, D. W., Barberis, J. N. \& Buckley, R. P. The Evolution of Fintech: A New Post-Crisis Paradigm? SSRN (2015). doi:10.2139/ssrn.2676553

11. Gurrea-Martínez, A. \& Remolina, N. The Law and Finance of Initial Coin Offerings. SSRN (2018). doi:10.2139/ssrn.3182261

12. Kaal, W. A. Initial Coin Offerings: The Top 25 Jurisdictions and Their Comparative Regulatory Responses. SSRN (2018). doi:10.2139/ssrn.3117224

13. Kaal, W. A. \& Dell'Erba, M. Initial Coin Offerings: Emerging Practices, Risk Factors, and Red Flags. SSRN (2017) doi:10.2139/ssrn.3067615

14. Fenu, G., Marchesi, L., Marchesi, M. \& Tonelli, R. The ICO phenomenon and its relationships with ethereum smart contract environment. in 2018 International Workshop on Blockchain Oriented Software Engineering (IWBOSE) 26-32 (2018) doi:10.1109/IWBOSE.2018.8327568

15. Tasatanattakool, P. \& Techapanupreeda, C. Blockchain: Challenges and applications. in International Conference on Information Networking (2018). doi:10.1109/ICOIN.2018.8343163

16. Jiasun, L. \& Mann, W. Regulation of Initial Coin Offerings. White Case (2018). doi:10.2139/ssm.3200037

17. Momtaz, P. P. Initial Coin Offerings. SSRN (2018) doi:10.2139/ssrn.3166709

18. Zheng, Z., Xie, S., Dai, H.-N. \& Wang, H. Blockchain Challenges and Opportunities: A Survey. Int. J. Web Grid Serv. 1-24 (2017) doi:10125/41338

19. Keidar, R. \& Blemus, S. Cryptocurrencies and Market Abuse Risks: It's Time for Self-Regulation. SSRN (2018). doi:10.2139/ssrn.3123881

20. Zalan, T. Born global on blockchain. Rev. Int. Bus. Strateg. (2018) doi:10.1108/RIBS-08-2017-0069
Published By:

Blue Eyes Intelligence Engineering

\& Sciences Publication 
21. Dorfleitner, G., Hornuf, L., Schmitt, M. \& Weber, M. FinTech in Germany. FinTech in Germany (2017) doi:10.1007/978-3-319-54666-7

22. Kakavand, H., Kost De Sevres, N. \& Chilton, B. The Blockchain Revolution: An Analysis of Regulation and Technology Related to Distributed Ledger Technologies. SSRN (2016). doi:10.2139/ssrn.2849251

23. Mackenzie, A. THE FINTECH REVOLUTION. London Bus. Sch. Rev. (2015). doi:10.1111/2057-1615.12059

24. Kuo Chuen, D. L. Fintech Tsunami: Blockchain as the Driver of the Fourth Industrial Revolution. SSRN (2017). doi:10.2139/ssm.2998093

25. Pierro, M. DI. What Is the Blockchain? Comput. Sci. Eng. (2017). doi:10.1109/MCSE.2017.3421554

26. Azaria, A., Ekblaw, A., Vieira, T. \& Lippman, A. MedRec: Using Proceedings - 2016 2nd International Conference on Open and Big Data, OBD 2016 (2016). doi:10.1109/OBD.2016.11

27. Campbell-Verduyn, M. Bitcoin and beyond: Cryptocurrencies, blockchains, and global governance. Bitcoin and Beyond: Cryptocurrencies, Blockchains, and Global Governance (2017). doi:10.4324/9781315211909

28. Jaag, C. \& Bach, C. Blockchain Technology and Cryptocurrencies: Opportunities for Postal Financial Services. in The Changing Posta and Delivery Sector (2017). doi:10.1007/978-3-319-46046-8 13

29. Benchoufi, M. \& Ravaud, P. Blockchain technology for improving clinical research quality. Trials (2017) doi:10.1186/s13063-017-2035-z

30. Takemoto, Y. \& Knight, S. Mt. Gox files for bankruptcy, hit with lawsuit. Reuters (2014).

31. Summers, T. C. Hacking the blockchain. Mod. Trader (2016).

32. Deng, H., Huang, R. H. \& Wu, Q. The Regulation of Initial Coin Offerings in China: Problems, Prognoses and Prospects. Eur. Bus. Organ. Law Rev. (2018). doi:10.1007/s40804-018-0118-2

33. Swan, M. Blockchain for Business: Next-Generation Enterprise Artificial Intelligence Systems. in Advances in Computers (2018). doi:10.1016/bs.adcom.2018.03.013

34. Fisch, C. Initial coin offerings (ICOs) to finance new ventures. J. Bus.

35. Portmann, E. Rezension „Blockchain: Blueprint for a New Economy“. HMD Prax. der Wirtschaftsinformatik (2018) doi:10.1365/s40702-018-00468-4

36. Buterin, V. A next-generation smart contract and decentralized application platform. Etherum

(2013). doi:10.1016/j.jchromb.2013.02.015

37. Fernández-Caramés, T. M. \& Fraga-Lamas, P. A Review on the Use of Blockchain for the Internet of Things. IEEE Access (2018) doi:10.1109/ACCESS.2018.2842685

38. Lundbaek, L. N. \& Huth, M. Oligarchic control of business-to-business blockchains. in Proceedings - 2nd IEEE European Symposium on Security and Privacy Workshops, EuroS and PW 2017 68-71 (2017). doi:10.1109/EuroSPW.2017.53

39. Berg, C., Davidson, S. \& Potts, J. Some Public Economics of Blockchain Technology. SSRN (2018). doi:10.2139/ssrn.3132857

40. Godsiff, P. Bitcoin: Bubble or blockchain. in Smart Innovation, Systems and Technologies (2015). doi:10.1007/978-3-319-19728-9_16

41. Ametrano, F. M. Hayek Money: The Cryptocurrency Price Stability Solution. SSRN (2014). doi:10.2139/ssrn.2425270

42. Anonym. Hackers turn to Bitcoin. SC Magazine: For IT Security Professionals (2014).

43. Bhardwaj, A., Avasthi, V., Sastry, H. \& Subrahmanyam, G. V. B. Ransomware Digital Extortion: A Rising New Age Threat. Indian $J$. Sci. Technol. (2016). doi:10.17485/ijst/2016/v9i14/82936

44. Kotov, V. \& Rajpal, M. S. Understanding Crypto Ransomware. Bromium (2014)

45. Marian, O. IS CRYPTOGRAPHIC CURRENCY AN OUTSTANDING TAX HEAVEN? J. ISTANBUL Univ. LAW Fac. Fak. MECMUASI (2016).

46. Iansiti, M. \& Lakhani, K. R. The truth about blockchain. Harvard Business Review 2017, (2017).

47. Buterin, V. Ethereum White Paper: A Next Generation Smart Contract \& Decentralized Application Platform. Ethereum (2013) doi:10.5663/aps.v1i1.10138

48. Khan, N., Lahmadi, A., François, J. \& State, R. Towards a management plane for smart contracts: Ethereum case study. in IEEE/IFIP Network Operations and Management Symposium: Cognitive Management in a Cyber World, NOMS 2018 (2018). doi:10.1109/NOMS.2018.8406326

49. Kuo, T. T., Kim, H. E. \& Ohno-Machado, L. Blockchain distributed ledger technologies for biomedical and health care applications. Journal of the American Medical Informatics Association (2017). doi:10.1093/jamia/ocx068 blockchain for medical data access and permission management. in Ventur. (2019). doi:10.1016/j.jbusvent.2018.09.007

50. Zheng, Z., Xie, S., Dai, H., Chen, X. \& Wang, H. An Overview of Blockchain Technology: Architecture, Consensus, and Future Trends. in Proceedings - 2017 IEEE 6th International Congress on Big Data, BigData Congress 2017 doi:10.1109/BigDataCongress.2017.85

51. Larios-Hernández, G. J. Blockchain entrepreneurship opportunity in the practices of the unbanked. Bus. Horiz. (2017) doi:10.1016/j.bushor.2017.07.012

52. Bhaskar, N. D. \& Chuen, D. L. K. Bitcoin Exchanges. in Handbook of Digital Currency: Bitcoin, Innovation, Financial Instruments, and Big Data (2015). doi:10.1016/B978-0-12-802117-0.00028-X

53. Bruens, B. \& Moehrle, M. G. Understanding the diffusion of the blockchain technology: A patent-based analysis using the tf-lag-idf for term novelty evaluation. in PICMET 2018 - Portland International Conference on Management of Engineering and Technology: Managing Technological Entrepreneurship: The Engine for Economic Growth, Proceedings (2018). doi:10.23919/PICMET.2018.8481994

54. Kondor, D., Pósfai, M., Csabai, I. \& Vattay, G. Do the rich get richer? An empirical analysis of the Bitcoin transaction network. PLoS One (2014). doi:10.1371/journal.pone.0086197

55. Chen, Y. Blockchain tokens and the potential democratization of entrepreneurship and innovation. Bus. Horiz. (2018) doi:10.1016/j.bushor.2018.03.006

56. Mittal, V. Blockchain tokens and the potential democratization of entrepreneurship and innovation. Bus. Horiz. (2018) doi:10.1016/j.bushor.2018.03.006

57. Benedetti, H. \& Kostovetsky, L. Digital Tulips? Returns to Investors in Initial Coin Offerings. SSRN (2018). doi:10.2139/ssrn.3182169

58. Coinbase. Buy and sell Cryptocurrency. (2017). Available at: https://www.coinbase.com/.

59. O’Hara, K. Smart Contracts - Dumb Idea. IEEE Internet Comput. (2017). doi:10.1109/MIC.2017.48

60. Krupp, J. \& Rossow, C. teether: Gnawing at ethereum to automatically exploit smart contracts. in USENIX Security Symposium (2018).

61. Zetzsche, D. A., Buckley, R. P., Arner, D. W. \& Föhr, L. The ICO Gold Rush: It's a Scam, It's a Bubble, It's a Super Challenge for Regulators. SSRN (2017). doi:10.2139/ssrn.3072298

62. Ernst \& Young. Big risks in ICO market Masthead Flawed token valuations ,. EY News (2018).

63. Triantafyllidis, N. P. Developing an Ethereum Blockchain Application. Syst. Netw. Eng. (2016).

64. Lipusch, N. Initial Coin Offerings - A Paradigm Shift in Funding Disruptive Innovation. SSRN (2018). doi:10.2139/ssrn.3148181

65. Tomaino, N. The token economy. Retrieved from https://thecontrol.co/the-token-economy-81becd26b9de (2017).

66. Yaqoob, I. et al. The rise of ransomware and emerging security challenges in the Internet of Things. Comput. Networks (2017) doi:10.1016/j.comnet.2017.09.003

67. Maslove, D. M., Klein, J., Brohman, K. \& Martin, P. Using Blockchain Technology to Manage Clinical Trials Data: A Proof-of-Concept Study. JMIR Med Inf. 6, e11949 (2018).

68. $\mathrm{Xu}, \mathrm{J} . \mathrm{J}$. Are blockchains immune to all malicious attacks? Financ. Innov. (2016). doi:10.1186/s40854-016-0046-5

69. Griggs, K. N. et al. Healthcare Blockchain System Using Smart Contracts for Secure Automated Remote Patient Monitoring. J. Med. Syst. (2018). doi:10.1007/s10916-018-0982-x

70. Broggi, Lilly \& Duquette. Building the first blockchain university. Woolf Dev. Ltd (2018)

71. Dettling, W. How to teach blockchain in a business school. in Studies in Systems, Decision and Control (2018). doi:10.1007/978-3-319-74322-6_14

72. Yang, O. Blockchain Learning System. High. Educ. Whisperer (2016).

73. Roman-Belmonte, J. M., De la Corte-Rodriguez, H. \& Rodriguez-Merchan, E. C. How blockchain technology can change medicine. Postgraduate Medicine (2018) doi:10.1080/00325481.2018.1472996

74. Cong, L. W. \& He, Z. Blockchain Disruption and Smart Contracts. SSRN (2017). doi:10.2139/ssrn.2985764

75. Savelyev, A. Contract law 2.0: 'Smart' contracts as the beginning of the end of classic contract law. Inf. Commun. Technol. Law (2017) doi:10.1080/13600834.2017.1301036

76. Omohundro, S. Cryptocurrencies, smart contracts, and artificial intelligence. AI Matters (2014). doi:10.1145/2685328.2685334

77. Makhdoom, I., Abolhasan, M., Abbas, H. \& Ni, W. Blockchain's adoption in IoT: The challenges, and a way forward. Journal of Network and Computer Applications (2019). doi:10.1016/j.jnca.2018.10.019 
78. Khan, M. A. \& Salah, K. IoT security: Review, blockchain solutions, and open challenges. Futur. Gener. Comput. Syst. (2018). doi:10.1016/j.future.2017.11.022

79. Potts, J., Rennie, E. \& Goldenfein, J. Blockchains and the Crypto-City. SSRN (2017). doi:10.2139/ssrn.2982885

80. Kim, T. hoon, Ramos, C. \& Mohammed, S. Smart City and IoT. Future Generation Computer Systems (2017). doi:10.1016/j.future.2017.03.034

81. Dorey, P. Securing the internet of things. in Smart Cards, Tokens, Security and Applications: Second Edition (2017). doi:10.1007/978-3-319-50500-8_16

82. Wu, X., Zhu, X., Wu, G. Q. \& Ding, W. Data mining with big data. IEEE Trans. Knowl. Data Eng. (2014). doi:10.1109/TKDE.2013.109

83. Schumacher, A. Reinventing Healthcare on the Blockchain: Toward a New Era in Precision Medicine. Blockchain Res. Inst. (2018). doi:10.1016/j.resp.2009.04.020

84. Kuo, T. T., Kim, H. E. \& Ohno-Machado, L. Blockchain distributed ledger technologies for biomedical and health care applications. Journal of the American Medical Informatics Association (2017). doi:10.1093/jamia/ocx068

85. Szewczyk, P. Potential Applications of the Blockchain Technology in Helthcare. Sci. Pap. Silesian Univ. Technol. Organ. Manag. (2017).

86. Adhami, S., Giudici, G. \& Martinazzi, S. Why do businesses go crypto? An empirical analysis of initial coin offerings. Journal of Economics and Business (2018). doi:10.1016/j.jeconbus.2018.04.001

87. Le Nguyen, T. Blockchain in healthcare: A new technology benefit for both patients and doctors. in PICMET 2018 - Portland International Conference on Management of Engineering and Technology: Managing Technological Entrepreneurship: The Engine for Economic Growth, Proceedings (2018). doi:10.23919/PICMET.2018.8481969

88. Catalini, C. The Potential for Blockchain to Transform Electronic Health Records. Harv. Bus. Rev. (2017).

89. Macrinici, D., Cartofeanu, C. \& Gao, S. Smart contract applications within blockchain technology: A systematic mapping study. Telematics and Informatics (2018). doi:10.1016/j.tele.2018.10.004

90. Atzei, N., Bartoletti, M. \& Cimoli, T. A survey of attacks on Ethereum smart contracts (SoK). in Lecture Notes in Computer Science (including subseries Lecture Notes in Artificial Intelligence and Lecture Notes in Bioinformatics) (2017) doi:10.1007/978-3-662-54455-6_8

91. Allen, D. Discovering and Developing the Blockchain Cryptoeconomy. SSRN (2016). doi:10.2139/ssrn.2815255

92. Duffield, E. \& Hagan, K. Darkcoin : Peer - to - Peer Crypto - Currency with Anonymous Blockchain Transactions and an Improved Proof - of - Work System. Mar-2014 [Online]. Available: https:/ (2014) doi:10.1016/0148-2963(92)90036-B

93. Moore, D. \& Rid, T. Cryptopolitik and the Darknet. Survival (Lond). (2016). doi:10.1080/00396338.2016.1142085

94. Pergolizzi, J. V., LeQuang, J. A., Taylor, R. \& Raffa, R. B. The "Darknet": The new street for street drugs. Journal of Clinical Pharmacy and Therapeutics (2017). doi:10.1111/jcpt.12628

95. Hacker, P. \& Thomale, C. Crypto-Securities Regulation: ICOs, Token Sales and Cryptocurrencies under EU Financial Law. SSRN (2017). doi:10.2139/ssrn.3075820

96. CSA. Canadian Securities Regulators Outline Securities Law Requirements That May Apply to Cryptocurrency Oferings. (2017).

97. Prisco, G. EU Parliament votes for smart regulation of blockchain technology. (2016). Available at: https://bitcoinmagazine.com/articles/eu-parliament-votes-for-light-ha nded-regulation-of-blockchain-technology-1464971927/.

98. Patrick, G. Europe's regulatory blockchain shift on display at private Parliament event. (2016). Available at: https://www.coindesk.com/the-eu-regulatory-blockchain-shift.

99. Nica, O., Piotrowska, K. \& Schenk-Hoppé, K. R. Cryptocurrencies. Economic Benefits and Risks. SSRN (2017). doi:10.2139/ssrn.3059856

100. Amsden, R. \& Schweizer, D. Are Blockchain Crowdsales the New 'Gold Rush'? Success Determinants of Initial Coin Offerings. SSRN (2018). doi:10.2139/ssrn.3163849

\section{AUTHORS PROFILE}

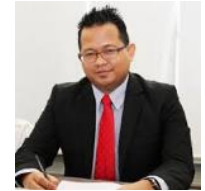

Wan Mohd Hirwani Wan Hussain $\mathrm{PhD}$ is enthusiastic and professionals, who enjoys being part of, as well as leading, a successful and productive team. Having over 10 years' experience in internet marketing, big data, blockchain, cryptocurrency, cloud computing, business analytics, search engine marketing (SEM), search engine optimization (SEO), business development, product, service and commercialization technology, he knows how to cost-effectively bring products and services to the market place. He has consulted with hundreds of customers about their business, E-commerce and internet solutions, helping them ensure a return on their technology investment. 